\title{
Development and validation of HPTLC fingerprints of three species of Alpinia with biomarker Galangin
}

\author{
Anuradha S. Upadhye ${ }^{1 *}$, Anagha Rajopadhye ${ }^{2}$ and Lourelle Dias ${ }^{1}$
}

\begin{abstract}
Background: Alpinia galanga (L.) Willd. commonly called as Rasna, Greater galangal or Kulinjan is a medicinally important rhizome used in Indian traditional system of medicine to cure a number of ailments. A. galanga is the main source of a galangin -a medicinally important flavanol which has a number of pharmacological properties viz. anti-mutagenic, and anti-inflammatory. Due to the high demand for the rhizome of A. galanga traders are now substituting it with rhizomes of $A$. calcarata and A. officinarum.

Methods: The present study aims to develop high performance thin layer chromatographic (HPTLC) fingerprinting of A. galanga with its adulterants or substitutes and to quantify bioactive galangin present thereof. Methanolic extracts were obtained from rhizomes of the three species of Alpinia used for HPTLC analysis using silica gel 60 F254 plates and hexane: ethyl acetate: acetic acid (6.2: 2.8: 1.0 V/v/V); the densitometric analysis was performed at $272 \mathrm{~nm}$.

Results: By comparison of $\mathrm{R} f$ values and of the spectra of the bands with those of the standard galangin was identified in all three samples. HPTLC quantitative analysis of the methanolic extracts showed the decline trend in the quantity of the galangin in the three species of Alpinia as A. galanga $(7.67 \pm 0.36 \mathrm{mg} / \mathrm{g})>$ A. officinarum $(5.77 \pm 0.71 \mathrm{mg} / \mathrm{g})>$ A. calcarata $(4.31 \pm 0.44 \mathrm{mg} / \mathrm{g})$. The HPTLC method was validated using International Conference on Harmonization $(\mathrm{ICH})$ guidelines. The HPTLC method showed good linearity, recovery and high precision of biomarker.
\end{abstract}

Conclusions: Rapid and reproducible method is useful for routine analysis of galangin and quality control of Alpinia galangal along with its adulterants or substitutes.

Keywords: Alpinia sp., Adulterants or substitutes, Galangin, Hptlc

\section{Background}

Genus Alpinia consist of 230 species from family Zingiberaceae [1]. One of these, rhizome of Alpinia galanga (L.) Willd. is used in Indian traditional system of medicine for rheumatism, fever, bronchial catarrh, stomach pain, stimulant, carminative, tonic, aphrodisiac, aromatic and to decrease the urine output in diabetic patients etc. [2]. It is commonly known as Greater galangal in English, Rasna in Sanskrit and traded as Kulinjan in Indian market [3]. It is native to Eastern

\footnotetext{
* Correspondence: upadhye.anuradha@gmail.com;

anuradhaupadhe@aripune.org

${ }^{1}$ Biodiversity and Palaeobiology, Agharkar Research Institute, G.G. Agarkar

Road, Pune 411004, India

Full list of author information is available at the end of the article
}

Himalaya and distributed in China, Malaya, Indonesia, Thailand, India [4] Philippines and Indonesia [5].

Rhizomes of A. galanga are reported for anti-microbial, anti-diabetic [6], anti-inflammatory, anti-cancer [7], antiflatulence [8], anti-fungal in AIDS patients [9], cytoprotective [10] and anti-allergic activity [11]. The chemical study reported presence of a wide array of bioactive phytoconstituents in the rhizome of $A$. galanga as galangin, $\alpha$-pinene, $\beta$-pinene, limonene, cineol, terpinen-4-ol, $\alpha$ terpineol, resin containing galangol, kaempferide, methyl cinnamate, camphor, myricene, methyl eugenol, flavones, alpinin, 3-deoxy-4-methoxy [12] and 1'-acetoxychavicol acetate [13]. Of which, it is a foremost source of flavonol galangin having the diverse source of biological and 
pharmacological properties, such as anti-mutagenic, anticlastogenic, antioxidative, anti-inflammatory [14], metabolic enzyme modulating, anti-proliferative and anticancer activity [15].

Crude drug samples of $A$. galanga commonly known as 'Kulinjan' were studied for their biological resource. Owing to its high demand in the Indian market, A. galanga is seen to be adulterated/substituted with rhizomes of two other species Alpinia calcarata (Haw.) Roscoe and Alpinia officinarum Hance under the common trade name $[16,11]$. In early research, $A$. calcarata has been used as a synonym for A. galanga [17]. However, as per recent nomenclature, both species are considered as separate entities.

HPTLC fingerprinting with bioactive marker confirms authenticity and quality of herbal medicine. A perusal of literature showed that reports on comparative HPTLC fingerprinting of herb A. galanga (rhizome) and its adulterants /substituent with reference to marker compound galangin was not available. Hence, the aim of present study was to develop a comparative HPTLC fingerprint of three species of Alpinia and quantification of galangin in the methanolic extract thereof using ICH guidelines [18].

\section{Methods}

\section{Chemicals and plant materials}

Standard galangin (CAS 548-83-4; Purity $\geq 98.0 \%$ ) was purchased from Fluka-Aldrich Chemical, Steinheim, Germany. Silica gel F254 HPTLC plates were purchased from Merck, Darmstadt, Germany. Other analytical grade solvents and regents were obtained from S. D. Fine chemicals, Mumbai, India.

Rhizomes of A. galanga and A. calcarata were collected from Dapoli and Naoroji Godrej Centre for Plant Research, Maharashtra, India in October 2013, respectively. The rhizomes of A.officinarum were procured from local Pune market in the same year. They were authenticated and deposited at Agharkar Herbarium of Maharashtra Association of Cultivation Science (AHMA) repository, Agharkar Research Institute, Pune 411,004; vide voucher specimen number R-199, R-200 and R-201.

\section{Preparation of sample solutions}

Accurately weighted (10 g) powdered samples were extracted exhaustively with methanol $(50 \mathrm{~mL})$ using Soxhlet apparatus with an extraction time of $480 \mathrm{~min}(8 \mathrm{~h})$. The extracts were concentrated under reduced temperature and pressure using rotary evaporator. Respective yields of methanol extract of samples were A. galanga (AGM) $0.990 \mathrm{~g}$, A. calcarata (ACM) $-0.867 \mathrm{~g}$ and A. officinarum (AOM) $-0.9501 \mathrm{~g}$.

\section{Chromatography}

HPTLC was performed on aluminium backed HPTLC plates $(10 \times 10 \mathrm{~cm})$ coated with $0.2 \mathrm{~mm}$ layers of silica gel 60 F254 (E. Merck, Germany). Samples were applied on the plate with band width $6 \mathrm{~mm}$ employing Linomat IV sample applicator (Camag, Switzerland) fitted with a microlitre syringe. Linear ascending development of the plates to a distance of $80 \mathrm{~mm}$ was performed with mobile phase hexane: ethyl acetate: acetic acid (6.2: 2.8: $1.0 \mathrm{v} / \mathrm{v} / \mathrm{v})$ in a twin trough glass chamber previously saturated with mobile phase vapour for $10 \mathrm{~min}$ at $25^{\circ} \mathrm{C}$. The dried plate was scanned at the wavelength of $272 \mathrm{~nm}$ ( $\lambda$ max of galangin) using a Camag TLC scanner 3 with CATS 4 software.

For the calibration curve, a standard stock solution $(1 \mathrm{mg} / \mathrm{mL})$ was prepared by dissolving $1 \mathrm{mg}$ accurately weighed galangin in methanol and diluting it to $10 \mathrm{~mL}$ in the volumetric flask. Working standard galangin solutions $3,6,9,12$ and $15 \mu \mathrm{g} / \mathrm{mL}$ of different concentrations; 50, 100, 150, 200 and $250 \mathrm{ng}$, respectively were prepared by diluting the stock solution. Each solution $(10 \mu \mathrm{L})$ was applied on the plate and the plate was developed under predetermined conditions described above. The procedure was repeated thrice to plot a graph of response (peak area) and amount of galangin.

\section{Quantification of galangin}

Suitably diluted solutions of test samples $(10 \mu \mathrm{L})$ were applied in triplicate on a HPTLC plate along with standard. The plate was developed under predetermined conditions described above and scanned at $272 \mathrm{~nm}$ ( $\lambda$ max of galangin). Peak areas were recorded and galangin content in the samples was calculated using the calibration plot (Fig. 1).

\section{Validation of the method}

The method was validated according to the ICH guidelines [18] by determining peak purity, limit of detection (LOD), limit of quantitation (LOQ), precision and recovery of galangin from the samples. LOD and LOQ were determined by diluting known concentrations of standard stock solution until the average responses were approximately three or ten times the responses of the blank.

Instrument precision was checked by repeated scanning of galangin band (200 ng) six times and was expressed as percent relative standard deviation (\% RSD). Precision was studied by analyzing six bands of sample solution per plate on three plates (intra-day precision) and by analyzing six bands of sample solution per plate on three consecutive days (inter-day precision) at three different amount (100, 150 and $200 \mathrm{ng})$ and calculated \% RSD. The accuracy of the method was tested by determination of recovery at three levels. Preanalyzed samples were spiked with extra galangin (50, 100 , and $150 \%$ ) and the mixtures were reanalyzed. The robustness of the method was studied at three different concentrations, such as 100, 150 and 200 ng per band 


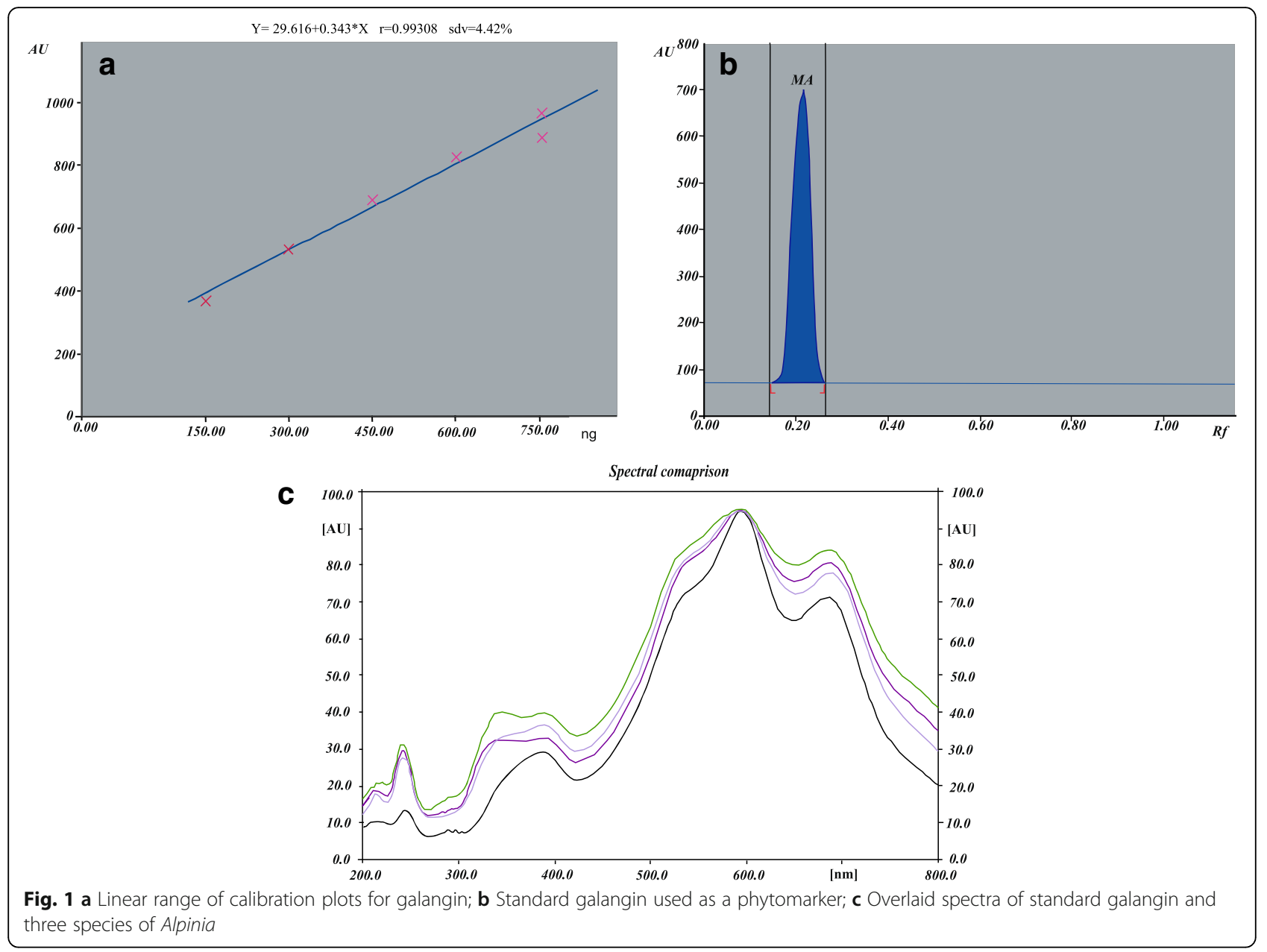

galangin by introducing small deliberate changes in mobile phase composition hexane: ethyl acetate: acetic acid (6.1: $2.8: 0.9 ; 6.3$ : 3: $0.8 ; 6.0: 3.1: 1.0 v / v / v)$. The repeatability of the method was assessed by analysis of $120 \mathrm{ng}$ per band of the standard solution of galangin $(n=6)$ and expressed as \% RSD of peak areas. Percentage recovery and standard deviation (SD) were calculated for each concentration level. LOD and LOQ were determined by

Table 1 Validation data of HPTLC method for the estimation of glangin

\begin{tabular}{ll}
\hline Intermediate precision (\% RSD, $n=6)$ & 0.72 \\
Calibration range (ng per spot) & $50-250$ \\
Regression equation & $\mathrm{Y}=0.313 \times+29.319$ \\
Correlation coefficient & 0.9919 \\
Repeatability of Standards (\% RSD, $n=6)$ & 0.91 \\
Repeatability of Samples (\% RSD, $n=6)$ & 0.83 \\
Limit of Detection (LOD) (ng per spot) & 15.15 \\
Limit of Quantitation (LOQ) (ng per spot) & 52.63 \\
Robustness (\% RSD, $n=3)$ & 0.79 \\
\hline
\end{tabular}

the standard deviation (SD) method from the slope (S) of the calibration plot and the SD of a blank sample (blank methanol was spotted three times), by use of the equations $\mathrm{LOD}=3.3 \times \mathrm{SD} / \mathrm{S}$ and $\mathrm{LOQ}=10 \times \mathrm{SD} / \mathrm{S}$.

\section{Chromatographic fingerprinting}

Chromatographic fingerprinting of three species of Alpinia along with bioactive marker galangin was developed using above chromatographic conditions.

\section{Statistical analysis}

The analysis of each processed extract of three Alpinia spp. was carried out in triplicates and results were reported as mean $\pm \mathrm{SD}$.

Table 2 Study of intra-day and inter-day precision for galangin

\begin{tabular}{lll}
\hline $\begin{array}{l}\text { Concentration } \\
\text { (ng per band) }\end{array}$ & $\begin{array}{l}\text { Intra-day } \\
(\% R S D, n=6)\end{array}$ & $\begin{array}{l}\text { Inter-day } \\
(\% R S D, n=6)\end{array}$ \\
\hline 100 & 2.89 & 4.17 \\
150 & 3.11 & 4.89 \\
200 & 1.05 & 2.27 \\
\hline
\end{tabular}


Table 3 Accuracy of the method for galangin

\begin{tabular}{|c|c|c|c|c|c|}
\hline \multirow[t]{2}{*}{ Sample extract } & \multicolumn{3}{|c|}{${\text { Amount of galangin }(n g)^{a}}^{a}$} & \multirow[t]{2}{*}{ Recovery (\%) ${ }^{\mathrm{a}}$} & \multirow[t]{2}{*}{ Average recovery $(\%)^{c}$} \\
\hline & Sample & Added & In mixture & & \\
\hline \multirow[t]{3}{*}{ A. galanga } & $640 \pm 20.89$ & 320 & $948 \pm 11.28$ & 98.75 & \multirow[t]{3}{*}{97.41} \\
\hline & $640 \pm 20.89$ & 640 & $1260 \pm 15.01$ & 96.88 & \\
\hline & $640 \pm 20.89$ & 960 & $1855 \pm 13.45$ & 96.61 & \\
\hline \multirow[t]{3}{*}{ A. calcarata } & $455 \pm 25.66$ & 227.5 & $623 \pm 8.89$ & 91.35 & \multirow[t]{3}{*}{93.69} \\
\hline & $455 \pm 25.66$ & 455 & $870 \pm 10.03$ & 95.60 & \\
\hline & $455 \pm 25.66$ & 682 & $1070 \pm 12.21$ & 94.11 & \\
\hline \multirow[t]{3}{*}{ A. officinarum } & $670 \pm 15.42$ & 335 & $941 \pm 10.74$ & 96.62 & \multirow[t]{3}{*}{94.37} \\
\hline & $670 \pm 15.42$ & 670 & $1263 \pm 17.28$ & 94.25 & \\
\hline & $670 \pm 15.42$ & 1005 & $1545 \pm 23.08$ & 92.24 & \\
\hline
\end{tabular}

${ }^{\mathrm{a}}$ Mean $\pm \mathrm{SD}(n=3)$

\section{Results and discussion}

Owing to the high automatization, HPTLC technique can be used for the analysis of complex mixtures of natural products. A clear recognition by United States Pharmacopeia [19] and Chinese Pharmacopoeia [20] points out the importance of this technique as the method of choice for handling complex analytical task involving herbal drugs and botanicals.

Herbal drugs are seen to be a mixture of phytoconstituents, in which no single constituent can be attributed for overall efficacy. Thus, it is necessary to establish certain quality control standards for raw materials and herbal products. Quantification of the content of marker present in herbal medicine is proving to be a standard method for evaluating the phytochemical entity of the herb. A flavonol, galangin is a bioactive constituent from Alpinia sp. The method will be helpful in determining the amount of galangin in different species of Alpinia which will provide significant advantages in terms of greater specificity and rapid analysis.

The mobile phase (hexane: ethyl acetate: acetic acid6.2: 2.8: $1.0 \mathrm{v} / \mathrm{v} / \mathrm{v}$ ) gave the optimized results with sharp, symmetrical and well-resolved peaks of galangin at $\mathrm{R} f$ 0.42 from other components of the sample extracts (Fig. 1). A linear relationship was obtained between response (peak area) and amount of galangin in the range of 50-250 ng/band; the correlation coefficient was 0.9919. A biomarker galangin in the methanolic extracts of three species of Alpinia was quantitated using the developed HPTLC method. The trend of galangin amount was found to be as $A$. galanga $(7.67 \pm 0.36 \mathrm{mg} / \mathrm{g})>A$. officinarum $(5.77 \pm 0.71 \mathrm{mg} / \mathrm{g})>$ A.calcarata $(4.31 \pm 0.44 \mathrm{mg} / \mathrm{g})$.

The method was validated in terms of peak purity, precision, LOD, LOQ and accuracy (Tables 1, 2 and 3) and was specific for analysis of active principle galangin because it resolved at $\mathrm{R} f 0.42$ in the presence of other components. Selectivity was shown by applying standard solutions to the plate. The purity of the galangin peak from the sample was confirmed by overlaying UV absorption spectrum of samples with standards at $272 \mathrm{~nm}$. The \% RSD of instrument precision for peak area of galangin was found to be 0.72 . Inter- and intraday precision were studied by triplicate assay at three different quantities (100, 150, $200 \mathrm{ng}$ per spot). Robustness of the method was indicated by low RSD values calculated of peak areas (Table 2). The accuracy of the method was determined at three levels $(50,100$, and $200 \%)$ by adding a known amount of standard to the sample extracts. Recovery varied between 93.69 to $97.41 \%$. High recovery indicated that the proposed method was reliable and reproducible (Table 3). LOD and LOQ were 15.15 and 52.63, respectively.

A precise and accurate HPTLC technique was developed, which allowed quantitative and qualitative evaluation of galangin in methanolic extracts of three species of Alpinia. Mobile phase optimized for HPTLC effectively resolved galangin.

This validity of data along with the HPTLC fingerprints for each individual species may help in correct identification of Alpinia spp. of important medicinal utility.

\section{Conclusions}

The rapid and reproducible method developed with HPTLC is useful for routine analysis of galangin and quality control of Alpinia galangal along with its adulterants or substitutes.

\footnotetext{
Acknowledgements

The authors are greatly thankful to the Director, Agharkar Research Institute, Pune, India for providing facilities and encouragement throughout the work. The second author is thankful to the authorities of Sinhgad College of Science, Pune, India.
}

\section{Funding}

The study was done under the in-house project of Agharkar Research Institute, Pune 411,004. 


\section{Availability of data and materials}

All data generated or analyzed during this study are included in this published article.

\section{Authors' contributions}

Basic idea: AU. Study design: AU and AR. Collection of the material: ASU, AR and LD. Technical work: AR and LD. Analysis: ASU, AR and LD. Interpretations: ASU and AR. Preparation of MS: ASU, AR and LD. All authors read and approved the final manuscript.

\section{Ethics approval and consent to participate}

This statement is not relevant to our MS.

\section{Consent for publication}

This statement is not relevant to our MS

\section{Competing interests}

The authors declare that they have no competing interests.

\section{Publisher's Note}

Springer Nature remains neutral with regard to jurisdictional claims in published maps and institutional affiliations.

\section{Author details}

'Biodiversity and Palaeobiology, Agharkar Research Institute, G.G. Agarkar Road, Pune 411004, India. ${ }^{2}$ Sinhgad College of Science, S.No. 9/1/5 \& 9/2/4, Off West. Bypass Highway, Ambegaon, Pune, Maharashtra 411041, India.

Received: 4 July 2017 Accepted: 28 November 2017

Published online: 16 January 2018

\section{References}

1. Raj G, Pradeep DP, Yusufali C, Dan M, Baby S. Chemical profiles of volatiles in four Alpinia species from Kerala, South India. J Essent Oil Res. 2013;25(2):97-102.

2. Shetty RG, Monisha S. Pharmacology of an endangered medicinal plant Alpinia galanga - a review. Res J Pharm Biol Chem Sci. 2015;6(1):499.

3. Anonymous, The Ayurvedic Pharmacopoeia of India. Government of India Ministry of Health and Family Welfare. New Delhi; 2006. 5(1) p.90-92.

4. Verma RK, Mishra G, Singh P, Jha KK, Khosa RL. Alpinia Galanga - an important medicinal plant: a review. Der Pharmacia Sin. 2011;2(1):142-54.

5. Yan WU, Ying W, Zhi-Hua LI, Cheng-Fang W, Jian-Yu W, Xiao-Lan LI, Ping-Juan W, Zhao-Feng Z, Shu-Shan DU, Dong-Ye H, Zhi-Wei D. Composition of the essential oil from Alpinia galanga rhizomes and its bioactivity on Lasioderma serricorne. Bull Insectol. 2014;67(2):247-54.

6. Jeyachandran R, Mahesh A. Enumeration of antidiabetic herbal flora of Tamil Nadu. Res J Med Plant. 2007:1 (4):144-8.

7. Kale VM, Namdeo AG. HPTLC densitometric evaluation by simultaneous estimation of galangin in Alpinia galanga and Alpinia officinarum. Der Pharmacia Lett. 2015;7(7):158-64.

8. Wungsintaweekul J, Sitthithaworn W, Putalun W, Hartwig WP, Brantner A. Antimicrobial, antioxidant activities and chemical composition of selected Thai spices. Songklanakarin J Sci Technol. 2010;32(6):589-98.

9. Udomkusonsri P, Trongvanichnam K, Klangkaew MLN, Napasorn KKJ. In vitro efficacy of the antifungal activity of some Thai medicinal-plants on the pathogenic fungus, Saprolegnia parasitica, from fish. Nat Sci. 2007:41:56-61.

10. Indrayan AK, Agrawal P, Rathi AK, Shatru A, Agrawal NK, Tyagi DK. Nutritive value of some indigenous plant rhizomes resembling ginger. Nat Prod Rad. 2009:8(5):507-13.

11. Namdeo AG, Kale VM. Comparative pharmacognostic and phytochemical investigation of two Alpinia species from Zingiberaceae Family. World J Pharm Res. 2015;4(5):1417-32.

12. Chudiwal AK, Jain DP, Somani RS. Alpinia galanga Willd. An overview on phyto pharmacological properties. Indian I Nat Prod Res. 2010;1 (2):143-9

13. Siringam K, Thongket T, Vajrodaya S, Mosaleeyanon K, Kirdmane C. Optimization of air temperature and medium $\mathrm{pH}$ enhanced growths and 1'-Acetoxychavicol acetate (ACA) content of galangal (Alpinia galanga) plantlets in vitro. KMITL Sci Tech J. 2012;12:30-8.
14. Tag H, Das AK, Loyi H. Anti inflammatory plants used by the Khamti tribe of Lohit district in eastern Arunachal Pradesh, India. Nat Prod Rad. 2007;6(4):334-40.

15. Madhuri S, Pandey G. Some anticancer medicinal plants of foreign origin. Curr Sci. 2009;96(6):780-3.

16. Girija TP, Rema SAB. Comparative anatomical and histochemical characterization of the source plants of the Ayurvedic drug Rasna., inter. J. Herbal Med. 2014;2(2):38-46.

17. Anonymous, Unani Pharmacopoeia of India. Government of India Ministry of Health and Family Welfare, Department of Ayurveda, Yoga \& Naturopathy (AYUSH). New Delhi; 2007; 2(1): 67-68.

18. International conference on harmonization $(\mathrm{ICH})$ of technical requirements for the registration of Pharmaceutical for Human use. In: ICH harmonized tripartite guideline validation of analytical procedures: text and methodology Q2(R1); 2012.

19. Anonymous. The United states pharmacopoeia, 31st Edition The national formulary, 26th edition, The United states pharmacopeia convention. Rockville; 2007.

20. Anonymous, TLC Atlas of Chinese crude drugs in pharmacopoeia of the People's Republic of China, Chinese Pharmacopoeia Commission People's Medical Publishing House; 2009.

\section{Submit your next manuscript to BioMed Central and we will help you at every step:}

- We accept pre-submission inquiries

- Our selector tool helps you to find the most relevant journal

- We provide round the clock customer support

- Convenient online submission

- Thorough peer review

- Inclusion in PubMed and all major indexing services

- Maximum visibility for your research

Submit your manuscript at www.biomedcentral.com/submit
Biomed Central 